\title{
Effect of Evidence Based Practice Training Program on Professional Nurses’ Decision Making Abilities
}

\author{
Mahdia Morsi El Shahat, Nora Ahmed Abd Allah \\ Nursing Administration, Faculty of Nursing, Benha University, Egypt \\ *Corresponding author: noraahmed9@Yahoo.com
}

Received November 18, 2018; Revised December 27, 2018; Accepted January 06, 2019

\begin{abstract}
Effective implementing of evidence based practice has potential benefits for professional nurses, patients, healthcare systems and reduces inappropriate deviations in healthcare practices, supplies a set of standards for enhancing clinical decision making abilities. Aim of the study: This study was aimed to assess of the effect of evidence based practice training program on professional nurses` decision making abilities. Design: A quasi experimental design was used in this study. Setting: This study was conducted at intensive care unit at Benha University Hospital and Benha Teaching Hospital. Subjects: A convenient sample of 68 professional nurses recruited from the presented units and had the following inclusion criteria; had a Bachelor degree in nursing science and willing to participate in the study. Tools for data collection: The study tools divided into four tools: EvidenceBased Knowledge Questionnaire, Evidence-Based Practice Questionnaire (EBPQ), Evidence-Based Practice Attitudes Scale and Decision Making Abilities Questionnaire. The results showed that, there was statistically significant improvement among the professional nurses' knowledge, skills, and attitudes regarding evidence based practice after implementation of the training program. There was highly statistical significant improvement in the professional nurses decision making abilities thorough program phases. As $40.7 \%$ of them were able to make decision before the program which improved to $67.4 \%$ immediate post the program and decrease to $60.3 \%$ three months follow up the program. The study concludes that, the implementation of the Evidence-Based Practice training program was significantly succeeded in enhancing total knowledge, skills, and attitudes of professional nurses that significantly improves their decision-making abilities. The study recommended that: Conduct continuous in-service training and education programs for refreshing and updating professional nurses knowledge and skills about the evidence-based practice. A brief basic educational intervention on EBP with online and face-toface learning can produce improvements in the knowledge and skills of clinical nurses.
\end{abstract}

Keywords: evidence-based practice, professional nurses, decision-making abilities, training program

Cite This Article: Mahdia Morsi El Shahat, and Nora Ahmed Abd Allah, "Effect of Evidence Based Practice Training Program on Professional Nurses' Decision Making Abilities.” American Journal of Nursing Research, vol. 7, no. 1 (2019): 93-101. doi: 10.12691/ajnr-7-1-13.

\section{Introduction}

Evidence-based practice is a problem-solving approach that involves the conscientious use of current best evidence in making decisions about patient care and conducting a systematic search for the most relevant evidence, as well as a critical appraisal of this evidence to answer a clinical question considering the nurses' expertise and patient values and preferences [1]. It is a clinical problem-solving strategy that de-emphasizes decision-making based on custom and emphasizes the integration of research evidence with clinical expertise and patient preferences. [2]. The goal of evidence-based practice is to provide practicing nurses with evidence-based data to deliver effective care based on the best research; resolve problems in the clinical setting; achieve excellence in care delivery, even exceeding quality assurance standards and to introduce innovation. Furthermore, evidence-based practice emphasizes the comprehensive evaluation of all relevant research according to a clinical question using a systematic review. Also, In EBP, healthcare professionals make clinical decisions based on the best available research results while considering the preferences and clinical circumstances of their patients. EBP implementation has been related to improved health outcomes $[3,4]$.

The process of evidence-based practice is a method that allows professional nurses to assess clinical research, guidelines and other information resources based on high-quality findings and apply the results to nursing practice. It is a problem-solving approach to clinical practice and administrative issues that integrates: A systematic search for and critical appraisal of the most relevant evidence to answer a burning clinical question, one's own clinical expertise patient preferences and attitudes. Moreover, this process include: cultivate a spirit of inquiry; Ask clinical questions in PICOT format which take into account patient population of interest (P), intervention or area of interest (I), comparison intervention or 
group $(\mathrm{C})$, outcome $(\mathrm{O})$, and time $(\mathrm{T})$; Search for the best evidence to inform clinical practice; critically appraise the evidence to determine which are most relevant, valid, reliable, and applicable to the clinical question; Integrate the evidence with clinical expertise and patient preferences and values; Evaluate the outcomes of the practice decisions or changes based on evidence; Disseminate evidence-based practice results [5].

Additionally, EBP is very important to clinical nurses to make informed clinical decisions by applying the best evidence to their care. And the deliberate use of available evidence in clinical decisions in combination with clinical expertise along with patients' concerns and preferences Evidence-based practice is a problem-solving process that consists of five sequential components: Formulating clinical answerable questions; seeking the most relevant evidence to the answers of these questions; critical appraisal of available evidence to determine its validity, relevance, and applicability; integrating and translating the research evidence and related knowledge into clinical practices; and reevaluating the appropriate application of the evidence and assessing the outcomes of various interventions and clinical decisions [6].

Decision-making is the thought process of selecting a logical choice from the available options. Also, it used to guide the nurse in assessing, assimilating, evaluating, and/or discarding components of information to make good judgments in clinical and non-clinical situations that are often feverish with activity and troubled with conflict. In practice, the nurse is required to make rapid decisions or choices under conditions of uncertainty. These choices are influenced by the subjective and objective information and data available to the nurse at the time of the decision [7]. Also, EBP is a direction to practice that values evidence as a resource for clinical decision-making while recognizing that evidence alone is never sufficient to make a clinical decision. Critics of EBP typically ignore, negate, or misrepresent the role of nurses thinking processes and expertise in clinical settings [8].

Decision-making ability for practice is an evidence-based guide for nurses that prepares to make effective decisions on the ward and in the community. The professional nurse must weigh the positives and negatives of each option, and consider all the alternatives when trying to make a good decision related to patient care especially, at Intensive Care Unit. For effective decision-making, a nurse must be able to forecast the outcome of each option as well and based on all these items, determine which option is the best for that particular situation $[9,10,11]$.

\subsection{Significance of the Study}

Professional nurses in Intensive Care Unit need the capabilities to continually update their practice and ensure that it is evidence-based. They need to be able to: Ask questions of their practice which are answerable with reference to evidence, search for the evidence to address their questions, critically appraise the evidence, synthesize the evidence to identify practice implications, Thus, nurses need applicable teaching strategies to provide them with adequate evidence-based practice knowledge and skills with positive attitudes toward integration within evidence-based practice activities. In this context, conducting an educational intervention to teach nurses about nursing research and evidence-based practice by offering a designed EBP training program to improve professional nurses' knowledge and skills and attitudes about using research and evidence-based practice, and improve nurses' decision-making abilities.

\subsection{Aim of the Study}

The study aimed to assess the effect of evidence-based practice training program on professional nurses` decision-making abilities.

\subsection{Research Hypothesis}

1. There will be a significant enhancement of professional nurses' knowledge, skills, and attitudes after implementing evidence-based practice training program than before.

2. There will be a significant improvement of professional nurses' decision-making abilities after implementing evidence-based practice training program than before.

\section{Subjects and Method}

\subsection{Research Design}

A quasi-experimental research design, with one group pre and posttest assessment, was used in conducting the present study.

\subsection{Setting}

The study was conducted at Intensive Care Units (ICU) at Benha University Hospital and Benha Teaching Hospital.

\subsection{Subjects}

A convenient sample of 68 professional nurses recruited from the presented units and had the following inclusion criteria; had the Bachelor degree in nursing science and willing to participate in the study.

\subsection{Tools of Data Collection}

Four tools were used to collect the study data.

\subsubsection{Evidence-Based Knowledge Questionnaire}

It was developed by the researchers to assess nurses' knowledge of evidence-based nursing practice based on Upton and Upton [12], and Fineout-Overholt, Melnyk [13]. It consisted of two parts.

Part I: Concerned with personal data of nurses such as (hospital, age, sex, marital status, years of experience and Hospital has access to database that might be used as a reference for EBP needed).

Part II: It consisted of 14 multiple choice questions with 5 multiple choice answers as (Evidence-Based Practice is identified as...). The nurses were encouraged to answers all the questions and select only the best correct answer. It was utilized during different phases of 
assessment (pre-program, immediately after program and 3 months follow up program)

Scoring System: The responses of nurses were given (1) for the right answer and (0) for the wrong answer. The scores were summed up and nurses' knowledge was considered satisfactory knowledge level with scores more than (75\%), fair knowledge level with scores from (75-60\%) and unsatisfactory knowledge level with scores less than (60\%).

\subsubsection{Evidence-Based Practice Questionnaire (EBPQ)}

It was developed by ${ }^{[12]}$ and modified by the researchers to assess nurses' skills about EBP. The questionnaire is a self-rating, asked the nurses to rate themselves on the implementation of EBP clinical activities and which includes research and information technology skills and ability to interpret the literature and apply it to particular activity cases. It consisted of 16 items as (How would you rate your skills to conduct online search using database and web search engines). It was utilized during different phases of assessment (pre-program, immediately after program and 3 months follow up program)

Scoring System: The responses of nurses were given on five-point Likert scale ranged from (1-5), (1) Poor, (2) fair, (3) good, (4) very good, and (5) excellent. The scores were summed up and a nurse was considered had high skill level more than (75\%), moderate skill level from (75-50\%) and low skill level less than (50\%).

\subsubsection{Evidence-Based Practice Attitudes Scale}

It was developed by the (Melynk, Fineout-Overholt, and Mays,) [14]. It was aimed to measure professional nurses' attitudes towards EBP. It consisted of (16 items) utilized during different phases of assessment (pre-program, immediately after program and 3 months follow up program).

Scoring system: The responses of nurses were measured using five-point Likert scale ranging from (1-5), (1) strongly disagree and (5) strongly agree. The scores were summed up and nurses attitude were considered had a highly positive attitude more than (75\%), positive attitude from (75-50\%) and negative attitude less than (50\%).

\subsubsection{Decision-Making Abilities Questionnaire}

It was developed by the researchers based on related literature $[15,16,17]$. It intended to assess the decision-making abilities of nurses. It was consisted of (12 items). It was utilized during different phases of assessment (pre-program, immediately after program and 3 months follow up program).

Scoring system: The responses of nurses were measured using three-point Likert scale ranging from (1-3), (1) rarely, (2) sometimes and (3) often. The professional nurse was considered able to make decision if the percent score was $60 \%$ or more and unable to make decision if the percent score less than $60 \%$.

\subsection{Data Collection Procedure}

\subsubsection{Administrative Approval}

An official approval was obtained from the Dean of Faculty of Nursing and the director of Benha University
Hospital and director of Benha Teaching Hospital, and from all participants in the study through official letters that sent to the heads of departments explaining the aim of the study. Assured complete confidentiality of the obtained information and the study would not affect in any the work or jeopardizes patient care. The results of the study, along with the recommendations will be forwarded to the hospital administration for possible application, to obtaining their permission and help in conduction and facilitate data collection.

Meetings were held between the researchers and the heads of Intensive Care Unit (ICU) at Benha University Hospital and Benha Teaching Hospital and professional nurses in unit. The aim of the study was discussed with them. The time for data collection and program implementation were also determined based on their views and workload to gain their approval and cooperation

\subsubsection{Tool Reliability and Validity}

The tools contents were developed and tested for its content validity through five expertise from nursing administration department. Based on their recommendations the necessary modifications were made for clarity of sentences and appropriateness of content. The internal consistency has been tested using Cronbach's alpha coefficient. Cronbach's alphas were $(r=0.90,0.91,0.89$, \& 0.86) for Evidence-Based Knowledge Questionnaire, Evidence-Based Practice Questionnaire (EBPQ), Evidence-Based Practice Attitudes Scale and DecisionMaking Abilities Questionnaire respectively.

\subsubsection{Pilot Study}

During August 2017, before collecting data, the revised questionnaires were piloted with $10 \%$ from the total sample ( 7 professional nurses) to test the clarity of questionnaires and to evaluate the effectiveness of the proposed data collection tools and assess the feasibility of the study. In addition to estimating the time needed to fill questionnaires. No modifications were done and professional nurses included in the pilot study were included in the main study subjects.

\subsubsection{Field Work}

Before beginning collecting data, a brief explanation of the aim of the study was given to the study subjects. Data collection was conducted throughout the following phases:

Phase 1 (assessment phase): Data collected during September 2017. Throughout this phase, Evidence-Based Knowledge Questionnaire, Evidence-Based Practice Questionnaire (EBPQ), Evidence-Based Practice Attitudes Scale and Decision-Making Abilities Questionnaire were distributed on the professional nurses to test the level of knowledge, skills, and the attitudes towards EBP and professional nurses' decision-making abilities in the pretest. The collected data analyzed to identify professional nurses' learning needs related to knowledge, skills and attitudes towards EBP.

Phase 2 (planning phase): During October 2017 according to the results of the pretest and extensive review of literature, the educational program on EBP was designed. The educational materials were designed after reviewing the related literature as the program booklet and 
the power point presentations. The EBP program booklet: Contained the program specification, objectives, timetable, and contents. The power-point presentations: Contained 3 main presentations (60\% theory) given over 3 sessions each session two hours, in addition to two sessions covered $40 \%$ practice on performing EBP activities, case studies and internet searching skills. The aim of the program was to assess effect of evidence-based practice training program on professional nurses` decision-making abilities. To achieve this aim, the program covered the following topics: Definition of evidence-based practice (EBP), nursing research, and evidence-based nursing, importance of EBP, goals of EBP, key component of EBP, evidence-based practice process, barriers to implementation of EBP, facilitators factors to EBP and nurses role in EBP.

Phase 3 (implementing phase): The program was conducted by the researchers for the period of two months, from November 2017 till December 2017. The subjects were divided to (7) groups according to their units, (2) groups at Benha Teaching Hospital and (5) groups at Benha University Hospital, each group was 10 professional nurses but one group at Benha University Hospital were 8 professional nurses. The program took about (2) days per week. Each researcher implemented the program with one group on the same day or different days according to unit workload and the program implemented in the morning and afternoon shifts. It begins with the aim of the current study, aim of the program, followed by discussion of the main topics of the program. At the end of the program, open discussion with the study subjects was done to answer any questions or explain any difficulties.

Phase 4 (evaluation phase): after conducting the program in January 2018 and February 2018, the post-test was done to examine to what extent the program improved the professional nurses knowledge, skills, attitudes toward EBP, and decision-making abilities. In period May 2018 the impact of the program was evaluated after three months follow up the program, using the same tools which were used before the program. And the results were analyzed and interpreted and clinical significance of finding evaluated for comprehended discussion of the data analysis results of the study.

\subsection{Ethical Consideration}

At the interview with professional nurses to collect data they informed about the purpose and benefits of the study, and they were informed that their participation is voluntary and they have the right to refuse to participate in the study without giving any reason. In addition, confidentially and anonymity of the subjects were assured the coding of all data.

\subsection{Limitation of the Study}

Sometimes, the sessions were interrupted and delayed due to over workload, noise that requires more time than the devoted as well as more effort.

\subsection{Statistical Analysis}

Data entry and analysis were done using statistical package for social science (SPSS) version 18. Data were presented using: Descriptive statistics in the form (frequency, percentage, mean and standard deviation, $t$. test and Chi-square). Test of significant was done. Significant level value was considered when $\mathrm{p} \leq 0.05$ and $\mathrm{a}$ highly significant level value was considered when $\mathrm{p} \leq$ 0.01 .

\section{Results}

Table 1: This table showed that more than two thirds (70.6\%) of professional nurses were working at Benha University Hospital, and slightly more than half of them were aged between 26-35 years. And $42.6 \%$ of them had more than 15 years of experience; also, $91.2 \%$ and $83.8 \%$ of professional nurses were female, single respectively. And all professional nurses agreed that the hospital hadn't access to database that might be used as a reference for EBP needed.

Table 2: Demonstrates that there was a statistically significant improvement in professional nurses` knowledge regarding evidence-based practice through the program phases. With Mean \pm SD 2.69 \pm 3.28 preprogram that improved to $10.22 \pm 2.17$ immediate post-program that decreases to $8.82 \pm 3.12$ follow up the program but still more than preprogram scores. As regarding professional nurses' skills regarding evidence-based practice, there was statistically significant improvement in their skills thorough the program phases. With Mean \pm SD $26.25 \pm 5.69$ preprogram that improved to $54.58 \pm 7.05$ immediate post-program that decrease to $40.50 \pm 4.33$ follow up the program but still more than preprogram scores. In relation to professional nurses attitude regarding evidence-based practice, there was statistically significant improvement in their attitude through the program phases. With Mean \pm SD 24.92 \pm 3.06 preprogram that improved to $49.55 \pm 7.15$ immediate post-program that decreased to $38.16 \pm 3.78$ follow up the program but still more than preprogram scores.

Table 3: Clarified that there were statistically significant differences among professional nurses related to knowledge, skills, and attitude of dimensions of evidence-based practice in immediate post-program and follow up the program than preprogram.

Figure 1: Illustrated that there was a highly statistical significant improvement in professional nurses decisionmaking abilities thorough program phases. As $40.7 \%$ of them were able to make decision before the program which improved to $67.4 \%$ immediate post the program and decrease to $60.3 \%$ three months follow up the program.

Table 4: Revealed that there was a statistically significant correlation between professional nurses` total knowledge score post-program with their decision-making abilities score Post-program. Also, there was a highly statistically significant correlation between professionalnurses` total skills score Post-program with their decision-making abilities score Post-program. Finally, there was no statistically significant correlation between professional nurses` total attitude score Post-program with their decision-making abilities score Post-program.

Table 5: Displayed that there were statistically significant differences between professional nurses` total 
knowledge score preprogram and immediate Post-program with their years of experience. Also, there was a statistically significant difference between professional nurses` total knowledge score Post-program and follow up program with their age.

This table showed that there was a highly statistically significant difference between professional nurses` total skills score preprogram and Post-program with their age. Also, the table demonstrated that there was highly statistically significant differences between professional nurses` total attitude score Post-program with their years of experience.

Finally, the table clarified that there was statistical significant correlation between professional nurses` decision-making abilities immediate Post-program and follow up program with their years of experience, and immediate Post-program with their age.

Table 1. Frequency distribution of studied Bachelor nurses according to their Personal characteristics (n=68)

\begin{tabular}{|c|c|c|c|}
\hline \multicolumn{2}{|l|}{ Variable } & No & $\%$ \\
\hline \multirow{2}{*}{ Hospital } & Benha University Hospital & 48 & 70.6 \\
\hline & Benha Teaching Hospital & 20 & 29.4 \\
\hline \multirow{4}{*}{ Age } & $<26$ years & 10 & 14.7 \\
\hline & $26-35$ years & 35 & 51.5 \\
\hline & $>35$ years & 23 & 33.8 \\
\hline & Mean \pm SD & \multicolumn{2}{|c|}{$30.28 \pm 4.31$} \\
\hline \multirow{4}{*}{ Years of experience } & $<5$ years & 21 & 30.9 \\
\hline & 5-10 years & 18 & 26.5 \\
\hline & $>15$ years & 29 & 42.6 \\
\hline & Mean \pm SD & \multicolumn{2}{|c|}{$16.18 \pm 3.62$} \\
\hline \multirow{2}{*}{ Sex } & Female & 62 & 91.2 \\
\hline & Male & 6 & 8.8 \\
\hline \multirow{2}{*}{ Marital status } & Single & 57 & 83.8 \\
\hline & Married & 11 & 16.2 \\
\hline \multirow{2}{*}{$\begin{array}{l}\text { Hospital has access to data base that might be used as a } \\
\text { reference for EBP needed }\end{array}$} & Yes & 0 & 00 \\
\hline & No & 100 & 100 \\
\hline
\end{tabular}

Table 2. Mean and standard deviation of Evidence-Based Practice Domains among professional nurses thorough program $(\mathrm{n}=68)$

\begin{tabular}{|c|c|c|c|c|c|c|c|c|}
\hline $\begin{array}{c}\text { Evidence-Based } \\
\text { Practice Domains }\end{array}$ & $\begin{array}{c}\text { Number of } \\
\text { items }\end{array}$ & $\begin{array}{c}\text { Pre program } \\
\text { Mean } \pm \text { SD }\end{array}$ & $\begin{array}{c}\text { Post-program } \\
\text { Mean } \pm \text { SD }\end{array}$ & $\begin{array}{c}\text { Follow up program } \\
\text { Mean } \pm \text { SD }\end{array}$ & t-test 1 & $\begin{array}{c}\text { P } \\
\text { value }\end{array}$ & t-test 2 & $\begin{array}{c}\text { P } \\
\text { value }\end{array}$ \\
\hline Knowledge & 14 & $2.69 \pm 3.28$ & $10.22 \pm 2.17$ & $8.82 \pm 3.12$ & 7.79 & $\mathbf{0 . 0 0 0} * *$ & $\mathbf{6 . 2 5}$ & $\mathbf{0 . 0 0 0} * *$ \\
\hline Skills & 16 & $26.25 \pm 5.69$ & $54.58 \pm 7.05$ & $40.50 \pm 4.33$ & $\mathbf{2 6 . 0 4}$ & $\mathbf{0 . 0 0 0} * *$ & 25.07 & $\mathbf{0 . 0 0 0} * *$ \\
\hline Attitude & 16 & $24.92 \pm 3.06$ & $49.55 \pm 7.15$ & $38.16 \pm 3.78$ & 25.92 & $\mathbf{0 . 0 0 0} * *$ & $\mathbf{2 0 . 1 2}$ & $\mathbf{0 . 0 0 0 * *}$ \\
\hline
\end{tabular}

* Statistically significant. $(P \leq 0.05)$, t-test 1: pre \& post, t-test 2: pre \& follow up.

Table 3. Distribution of professional nurses according to their knowledge, skills and attitude regarding dimensions of Evidence-Based Practice thorough program $(n=68)$

\begin{tabular}{|c|c|c|c|c|c|c|c|c|c|}
\hline \multirow{2}{*}{\multicolumn{2}{|c|}{ Evidence-Based Practice Dimensions }} & \multicolumn{2}{|c|}{ Pre program } & \multicolumn{2}{|c|}{ Post-program } & \multicolumn{2}{|c|}{ Follow up program } & \multirow{2}{*}{$\mathrm{X} 2$} & \multirow{2}{*}{$\begin{array}{c}\mathbf{P} \\
\text { value }\end{array}$} \\
\hline & & No & $\%$ & No & $\%$ & No & $\%$ & & \\
\hline \multirow{3}{*}{ Knowledge } & Satisfactory & 10 & 14.7 & 30 & 44.1 & 28 & 41.2 & \multirow{3}{*}{124.24} & \multirow{3}{*}{$0.000 * *$} \\
\hline & Fair & 8 & 11.8 & 28 & 41.2 & 24 & 35.3 & & \\
\hline & Unsatisfactory & 50 & 73.5 & 10 & 14.7 & 16 & 23.5 & & \\
\hline \multirow{3}{*}{ Skills } & High & 2 & 2.9 & 34 & 50.0 & 11 & 16.2 & \multirow{3}{*}{108.8} & \multirow{3}{*}{$0.000 * *$} \\
\hline & Moderate & 11 & 16.2 & 31 & 45.6 & 40 & 58.8 & & \\
\hline & Low & 55 & 80.9 & 3 & 4.4 & 17 & 25.0 & & \\
\hline \multirow{3}{*}{ Attitude } & Highly positive & 0 & 0.0 & 31 & 45.6 & 7 & 10.3 & \multirow{3}{*}{92.10} & \multirow{3}{*}{$0.000 * *$} \\
\hline & Positive & 13 & 19.1 & 28 & 41.2 & 38 & 55.9 & & \\
\hline & Negative & 55 & 80.9 & 9 & $1 . .2$ & 23 & 33.8 & & \\
\hline
\end{tabular}

*Statistically significant. $(\mathrm{P} \leq 0.05)$

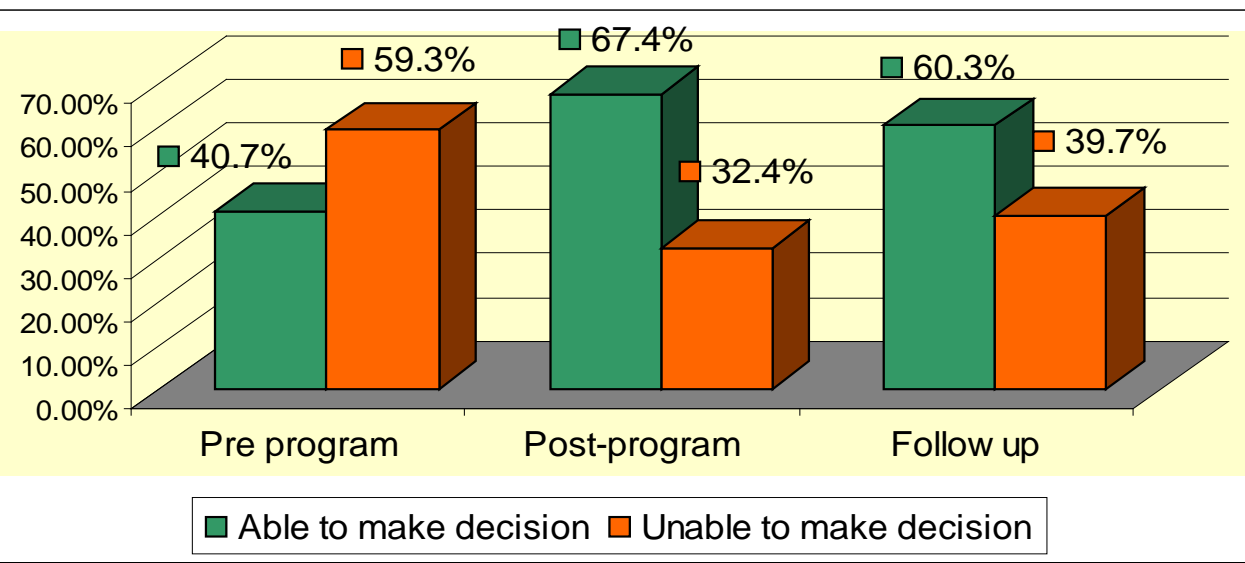

Figure 1. Percentage distribution of total decision-making abilities scores among Bachelor nurses thorough program (n=68). 
Table 4. Correlation between professional nurse``knowledge, skills, attitude regarding EBP and their decision-making abilities

\begin{tabular}{|c|c|c|c|c|c|c|}
\hline \multirow{3}{*}{$\begin{array}{c}\text { Decision-making abilities } \\
\text { score Post-program }\end{array}$} & \multicolumn{5}{|c|}{ Evidence-Based Practice Dimensions } \\
\cline { 2 - 7 } & Total knowledge score Post-program & Total skills score Post-program & \multicolumn{2}{|c|}{ Total attitude score Post-program } \\
\cline { 2 - 7 } & $\mathbf{r}$ & $\mathbf{P}$ & $\mathbf{r}$ & $\mathbf{P}$ & $\mathbf{r}$ & $\mathbf{p}$ \\
\cline { 2 - 7 } & 0.254 & $0.049^{*}$ & 0.660 & $0.000^{* *}$ & 0.190 & 0.142 \\
\hline
\end{tabular}

* Statistically significant. $(\mathrm{p} \leq 0.05)$.

Table 5. Correlation between the Bachelor nurses 'personal characteristics and their knowledge, skills, and attitude regarding Evidence-Based Practice (n=68)

\begin{tabular}{|c|c|c|c|c|}
\hline \multirow{2}{*}{ Items } & \multicolumn{2}{|c|}{ Age } & \multicolumn{2}{|c|}{ Years of experience } \\
\hline & $\mathrm{r}$ & $\mathrm{P}$ & $r$ & $\mathrm{P}$ \\
\hline \multicolumn{5}{|c|}{ Total knowledge score } \\
\hline Pre & 0.089 & 0.472 & 0.266 & $0.028 *$ \\
\hline Post & 0.294 & $0.015^{*}$ & 0.280 & $0.021^{*}$ \\
\hline Follow up & 0.877 & $0.019 *$ & 0.039 & 0.751 \\
\hline \multicolumn{5}{|c|}{ Total skills score } \\
\hline Pre & 0.593 & $0.000 * *$ & 0.022 & 0.861 \\
\hline Post & 0.808 & $0.000 * *$ & 0.051 & 0.678 \\
\hline Follow up & 0.123 & 0.317 & 0.041 & 0.742 \\
\hline \multicolumn{5}{|c|}{ Total attitude score } \\
\hline Pre & 0.029 & 0.813 & 0.049 & 0.694 \\
\hline Post & 0.030 & 0.808 & 0.280 & $0.021 *$ \\
\hline Follow up & 0.036 & 0.773 & 0.115 & 0.349 \\
\hline \multicolumn{5}{|c|}{ Decision-making abilities } \\
\hline Pre & 0.039 & 0.750 & 0.065 & 0.596 \\
\hline Post & 0.968 & $0.005^{* *}$ & 0.881 & $0.018^{*}$ \\
\hline Follow up & 0.138 & 0.263 & 0.660 & $0.000 * *$ \\
\hline
\end{tabular}

*Statistically significant. $(\mathrm{p} \leq 0.05)$.

\section{Discussion}

Evidence-based practice has key importance to the professional nurse's role regarding 'bridge the divide' between research and practice via improvement of clinical care on the basis of the evidence regarding best practice. Nursing becomes a 'research based career' and it is not enough to have knowledge of the best evidence to guide clinical practice; that knowledge must be translated into clinical practice to improve patient care and outcomes. Because evidence-based practice (EBP) is known to improve the quality of healthcare and patient outcomes as well as decrease healthcare costs and improve clinical decision-making abilities, there is currently an increased emphasis in clinical settings on promoting EBP among professional nurses especially at critical care units [18].

The present study was conducted to assess of effect of evidence-based practice training program on professional nurses`decision-making abilities. And research hypothesis: There will be significant enhancement of professional nurses' knowledge, skills and attitudes after implementing evidence-based practice training program. There will be significant improvement of professional nurses' decision-making abilities after implementing evidence-based practice training program.

The findings of the current study showed that there was a statistically significant improvement in professional nurses` knowledge regarding (EBP) thorough the program phases. This may be due to the ability of the professional nurses to gain knowledge easily and they are interested in the research topics. Also, they are professional nurses and they already in their academic study in faculty of nursing practicing scientific research as students when doing their assignments and presentation. Also, this improvement in knowledge can be influenced by the rate of memorization, ability of knowledge acquisition, the accumulation of learned knowledge of life, and the refreshing information using different approach of active learning during implementation of training program, such as work activities and group discussion, brainstorming, group activities, ... etc.

The result of present study was in agreement with Ali, [19]. who conduct study about" enhancing Bachelor nurses to use EBP in clinical practice" who stated that there was highly statistical significance improvement after the education intervention of the EBP teaching program and. The overall positive change in the nurses' knowledge after the teaching program reflected that education can bring about change in knowledge level.

Regarding professional nurses' skills regarding evidence-based practice, the finding of the current study revealed that there was statistically significant improvement in their skills thorough the program phases. This may be due to that focus and filling EBP training was supposed to be more likely to diminish barriers and struggle to adopt EBP and also ongoing educational program for nurses can profitably have an effect on nursing performance and skills especially at intensive care unit. So nurses' skills were improved after educational program which will beneficially reflected on nurse's desire and ability to keep their knowledge and skills up to date to be able to adopt EBP as a mean for improving their nursing care and decision-making abilities.

This finding may support by Bailey [20], who conduct study about " Educating nursing staff in evidence-based practice: A process improvement, development, and 
implementation of a preadmission clinic " who stated that in his study "that the participants had a limited knowledge and understanding of EBP and after the education presentation three quarters of the respondents indicated that the education helped them gain a better understanding of what EBP is and how to use it to improve processes and nursing practice." In the same context Eldeep and Bakeer [21] who conduct study about "Effect of an educational program interns' evidence-based program attitude, knowledge and skills and who were reported that the highest score percentage of the study subject reported high skills related to EBP' domains in Post-program than preprogram scores.

This finding is congruent with other similar study by Hart et al., [22], who conduct study about "Effectiveness of a computer-based educational program on nurses' knowledge, attitude, and skill level related to evidencebased practice." Who were revealed that conduction of an educational intervention improve nurses' skills about using research and evidence-based practice. In the same context Goot et al., [23], who conduct study about" The effect of a multifaceted evidence-based practice programme for nurses on knowledge, skills, attitudes, and perceived barriers: A cohort study; who were reported" our multifaceted in-house EBP programmed led to a significant improvement of approximately $40 \%$ in EBP knowledge and skills of participating nurses. Most nurses who followed the EBP programmed are currently applying their knowledge and skills in nursing practice."

In relation to nurses`attitude regarding evidence-based practice, there was a statistically significant improvement in their attitude through the program phases. From the researchers' point of view, this finding it means that the professional nurses have positive attitudes that were improved through the implementation of an education program on evidence-based practice. Several studies carried out in various contexts have reported that nurses have positive attitudes towards research and EBP Andersson et al., [24] , Stoke, et al., [25], who were conducted study" Professional roles and research utilization in pediatric care: Newly-graduated nurses' experiences " and the second conduct study about " Evidence-based practice beliefs and implementation among nurses: A cross-sectional study" founded that nurses having positive attitudes towards EBP and being able to see the value of evidence-based practice for patients have been reported as important for the implementation of evidence-based practice among nurses

Additionally this finding agreement with Kim et al., [26], who conduct a study about "Regional evidence-based practice fellowship program: Impact on evidence-based practice implementation and barriers" reported that scores for the attitude of all participants toward EBP were high after the intervention than before. This finding also agreed with Mooney [27], who about conduct study "The effect of education on evidence-based practice and nurses' beliefs/attitudes toward and intent to use evidence-based practice". He stated that education program can make a positive change in the nurses' beliefs/attitudes to use EBP". This finding Incongruent with findings of Gale and Schaffer [28], who conduct a study about " Organizational readiness for evidence-based practice" reported that nurses had little time either during scheduled working hours or during their personal time to engage in activities required for EBP".

The findings of the current study illustrated that there was a highly statistically significant improvement in professional nurses decision-making abilities thorough program phases. This may be that EBP process focuses on incorporating good information-seeking habits into a daily routine, therefore the professional nurses were asked to do self-rating to their frequency in seeking different information resources when making clinical decision and nursing care. This finding was in agreement with Thompson et al., [29], who conduct a study about " An agenda for clinical decision-making and judgment in nursing research and education " who pointed to that there was a highly statistically significant improvement in professional nurses decision-making abilities three phases program". Also, Stokke et al., [25], who conduct study about "Evidence-based practice beliefs and implementation among nurses: A cross-sectional study" who reported that a high significantly, level of clinical decision-making expertise based on extensive skills and knowledge after implementation the program.

The findings of the current study revealed that there was statistically significant correlation between professional nurses` total knowledge score Post-program with their decision-making abilities score Post-program. Also, there was a highly statistically significant correlation between professional nurses` total skills score Post-program with their decision-making abilities score Post-program. Finally, there was no statistically significant correlation between professional nurses` total attitude score Post-program with their decision-making abilities score Post-program. This might be due to the impact of implementing educational program evidence-based practice on the professional nurses' knowledge, skills and attitude and increasingly nurses determined to take into account evidence within the decision-making processes in their usual clinical practice. This finding was in agreement with Ali [19], Thorsteinsson [30], who were conduct studies about "Enhancing Bachelor nurses to use evidence-based nursing in clinical practice" and "An agenda for clinical decision-making and judgment in nursing research and education " who were reported that "positive correlation between nurses` total knowledge, total skills and total attitude score Post-program with their decision-making abilities score Post-program.

This finding displayed that there were statistically significant differences between professional nurses` total knowledge score preprogram and immediate Post-program with their years of experience. Also, there was a statistically significant difference between professional nurses` total knowledge score Post-program and follow up the program with their age. In researchers' point of view, this is explained as professional nurses can utilizing creative learning approaches and also due to the older and highly qualified nurses were more using research and application in their work. This finding disagreement with Salem et al. [31], who conduct study about "Knowledge, Practice and Attitude of Evidence-Based Practice Among Nurses in Kingdom of Saudi Arabia" who reported there are no statistically significant differences between nurses knowledge and their age and also stated that most experience nurses rely more on intuition and organizational tradition rather than on research findings". 
This finding showed that there were highly statistically significant differences between professional nurses` total skills score preprogram and Post-program with their age. This finding was in agreement with Goot, et al., 2018 [23], who conduct a study about "The effect of a multifaceted evidence-based practice programme for nurses on knowledge, skills, attitudes, and perceived barriers: A cohort study" who reported that "significant difference between expert nurses` total skills score Post-program with their personal characteristic".

Also, the finding of the present study demonstrated that there were statistically significant differences between professional nurses` total attitude score Post-program with their years of experience. This finding was supported by Majid, et al., [32], who conduct study about "Adopting evidence-based practice in clinical decision-making: Nurses' perceptions, knowledge, and barriers" who stated that "the majority of the nurses working in public hospitals in Singapore had a positive attitude toward EBP and nurses who had long experience in nursing were likely to be more confident in implementing EBP". This finding disagreed with Elsayed, et al., [33], who were conduct study about "Relation between Nursing Informatics Competency and Nurses’ Attitude toward Evidence-Based Practice among Qualified Nurses" who proved that "no statistical significant correlation between total score of the professional nurses' attitude toward evidence-based practice and their personal characteristics related to age and years of experience in their current position in the hospital".

The findings of the present study showed that there was statistically significant correlation between professional nurses` decision-making abilities immediate Post-program and follow up program with their years of experience and Post-program with their age. This could be due to increasing years of experience and age of professional nurses improve their decision-making abilities that will increase their ability to solve the complex problem during their clinical practice. This finding supported by Muntean, [34], who reported that" clinical experience adds to the practical and functional knowledge that nurses need to make complex decisions".

\section{Conclusion}

There was a statistically significant improvement in total knowledge, skills, and attitudes of professional nurses after implementation EBP training program. Also, there was a highly statistically significant improvement in professional nurses' decision-making abilities thorough program phases and also, there was a statistically significant correlation between professional nurses` total knowledge, total skills, and total attitudes score Post-program with their decision-making abilities score Post-program.

\section{Recommendations}

Based on the findings of the current study, the following recommendations can be suggested:
1. Conduct continuous in-service training and education programs for refreshing and updating nurses' knowledge and skills about the evidencebased practice.

2. Provide educational preparation in a hospital structure to focusing efforts on research utilization and evidence-based practice.

3. Developing EBP guidelines and protocols, allocate resources for rapid uptake of evidence-based practice in healthcare settings such as (internet source).

4. Hospital management support to create conducive environment and provide socializing opportunities for nurses to promote peer-to-peer information and knowledge sharing.

5. A brief basic educational intervention on evidencebased practice with online and face-to-face learning can produce improvements in the knowledge and skills of clinical nurses.

6. Publishing posters containing tips about search skills in evidence-based practice at each department.

7. Replication of the research on a large probability sample to determine the effect of the program on nursing practice and quality of patient care.

\section{References}

[1] Health Science Library, (2018). Basic Introduction to evidence-based practice resources. Available at: https://hsl.uw.edu. Retrieved on 20-8-2017.

[2] Karkada, S., (2015). Evidence based practice (EBP). International Journal of Nursing Research and Practice, 12 2. (2). 2-4.

[3] Heydari, A. ., Mazlom, S. R., Ranjbar, H \& Scurlock-Evans, and L. A., (2014). Study of Iranian nurses' and midwives' knowledge, attitudes, and implementation of evidence-based practice: The time for change has arrived. Worldviews on Evidence-Based Nursing, 11: 325-331.

[4] Marion, J. Ball \& Judith, V., (2011). Nursing Informatics: Where Technology and Caring Meet. Springer Co. $\left(4^{\text {th }} \mathrm{Ed}\right)$.

[5] Colorado Mesa University, (2016). Why evidence-based practice is vital to improving patient care. Available at:

https://degree.coloradomesa.edu/ Retrieved on: 24-8-2017.

[6] Koehn, M. L \& Lehman, K. (2012). Nurses' perceptions of evidence-based nursing practice. Journal of Advanced Nursing, 62 (2): 209-215.

[7] Morcillo, A. R., Salazar,S Martínez, M., Casado, R. D., (2015). Effectiveness of a brief, basic evidence based practice course for clinical nurses. Journal of Nursing Scholarship 12(4) 199-207.

[8] Karkada, S., (2015). Evidence based practice (EBP). International Journal of Nursing Research \& Practice, 1 2. (2) 2-4

[9] Pearson A., \& Jordan Z., (2013). Evidence-based healthcare in developing countries, International Journal of Evidence-Based Healthcare, 8 (2): 97-100.

[10] Stanley, G, M \& Jeanne, C. M., (2017). Practionior expertise in evidence based practice decision making. Social Work Practice, 18(4): 301-310.

[11] Mokhtar I. A., Majid, S., Foo, S., Zhang, X., Theng Y. L \& Chang Y. K., (2012). Evidence-based practice and related information literacy skills of nurses in Singapore: An exploratory case study. Health Informatics Journal. (18):12-25.

[12] Upton, D \&Upton, P (2006). Development of an evidence-based practice questionnaire for nurses. J Adv Nurs 53: 454-458.

[13] Fineout-Overholt, E \& Melnyk, F. M. (2011). Evidence-Based Practice in Nursing and Healthcare. ( $2^{\text {nd }}$ Ed). Philadelphia, PA: Lippincott Williams \& Wilkins Co. pp, 73-81, 205-213.

[14] Melnyk, B; Fineout-Overholt, E \& Mays, M., (2008). The evidence-based practice beliefs and implementation scales: psychometric properties of two new instruments, Worldviews on Evidence-Based Nursing, 5(4): 208-216. 
[15] Pearson, H. (2013). Science and intuition: Do both have a place in clinical decision making? British Journal of Nursing, 22(4), 212-215.

[16] Younis, S. (2017). Assessment of Problem-Solving Skills and Factors Influencing Decision Making among Nursing Management Staff, Unpublished Master Thesis, Faculty of Nursing, Benha University.

[17] Abd El-Ghaffar, M. (2017). Assessment of decision making ability among head nurses and its relation to their job satisfaction at Benha University Hospitals, Unpublished Master Thesis, Faculty of Nursing, Benha University.

[18] Hunter B. (2013). Implementing research evidence into practice: some reflections on the challenges. Evidence Based Midwifery, 11 (3): 76-80.

[19] Ali, K. A. G., (2014). Enhancing Bachelor nurses to use evidencebased nursing in clinical practice. Unpublished Doctorate thesis (Ph.D.) in Nursing Service Administration. Faculty of Nursing Benha University. P.140.

[20] Bailey, D. (2015). Educating nursing staff in evidence-based practice: A process improvement, development, and implementation of a preadmission clinic, A DNP Project Presented in partial fulfillment of the requirements for the degree doctor of nursing practice, Capella University.

[21] Eldeep, G. A and Bakeer, H. M., (2016). Effect of an educational program interns' evidence based program attitude, knowledge and skills. JOSR Journals of Nursing and Health Science. 5(3):12-18.

[22] Hart, P., Eaten, L., Buckner, M., Morrow B. N., Barrett, D. T., \& Fraser D. D., (2017). Effectiveness of a computer-based educational program on nurses' knowledge, attitude, and skill level related to evidence-based practice. Worldviews on Evidence-Based Nursing, 5(2), 78-84.

[23] Goot, W. E., Keers, J.C., Kuipers, R., Nieweg, R. M. \& Groot, M. D. (2018). The effect of a multifaceted evidence-based practice programme for nurses on knowledge, skills, attitudes, and perceived barriers: A cohort study. Nurse Education Today. 63: 5-11.

[24] Andersson, N., Cederfja“, C., Jylli, L., Nilsson, K. K \& Klang, B., (2012). Professional roles and research utilization in paediatric care: newly-graduated nurses' experiences, Scandinavian Journal of Caring Sciences 21(1), 91-97.

[25] Stokke, K., Olsen, N. R., Espehaug, B., \& Nortvedt M. W., (2014). Evidence, based practice beliefs and implementation among nurses: A cross-sectional study, BMC Nursing, Volume 13.
[26] Kim, S. C., Brown, C. E., Ecoff, L., Davidson, J. E., Gallo, A. M., Klimpel, K., \& Wickline, M. A., (2013). Regional evidence-based practice fellowship program: Impact on evidence-based practice implementation and barriers. Clinical Nursing Research, 22(1), 51-69.

[27] Mooney, S., (2012). The effect of education on evidence-based practice and nurses' beliefs/attitudes toward and intent to use evidence-based practice. Gardner-Webb University. A capstone project submitted to the faculty of Gardner-Webb University School of Nursing in partial fulfillment of the requirements for the degree of Doctorate of Nursing Practice.

[28] Gale \& Schaffer, (2014). Organizational readiness for evidencebased practice. Journal of Nursing Administration, 39 (2), 91-97.

[29] Thompson, C., Aitken, L., Doran, D., \& Dowding D., (2013). An agenda for clinical decision making and judgment in nursing research and education. International Journal of Nursing Studies 50 (12) $1720-1726$.

[30] Thorsteinsson S. Hrund J. (2014). Readiness for and predictors of evidence-based practice of acute-care nurses: a cross-sectional postal survey, Scandinavian Journal of Caring Sciences, Volume 28, Issue 3, pages 572-581.

[31] Salem, O. A., Alamrani, D \& Albloushi M. M., (2015). Knowledge, Practice and Attitude of Evidence Based Practice among Nurses in Kingdom of Saudi Arabia. The King Saud University, College of Nursing, Riyadh, Saudi Arabia. Med. J. Cairo Univ., 77(2), 121-128.

[32] Majid, S. h., Foo, L.B; Zhang, X; Theng, Y. L., Yun-K, C; \& Mokhtar, I. A., (2015). Adopting evidence-based practice in clinical decision making: Nurses' perceptions, knowledge, and barriers. J Med Libr Assoc 99(3).

[33] Elsayed, W. A., Hassona, F. \& Othman's, W. N., (2017). Relation between Nursing Informatics Competency and Nurses' Attitude toward Evidence-Based Practice among Qualified Nurses at Mansoura Oncology Center. International Journal of Nursing, 7: (6). 229. 26-33.

[34] Muntean, W. J., (2015). Nursing clinical decision-making: A Literature Review. Available at: https://www.ncsbn.org. Retrieved on: 24-7-2018. 